JKTP Vol 3 No (4) November (2020): 435-447

JKTP Jurnal Kajian Teknologi Pendidikan

DOI:10.17977/um038v3i42020p435

http://journal2.um.ac.id/index.php/jktp/index

\title{
PENERIMAAN DAN PENGGUNAAN E-LEARNING PADA MASA PANDEMI COVID-19: APLIKASI MODEL UTAUT2
}

\author{
Dede Kurnia \\ Pendidikan Ekonomi, STKIP Majenang \\ Jl. Raya Pahonjean KM. 2 Majenang, Kab. Cilacap, Jawa Tengah \\ Email: dedekurnia50@gmail.com
}

\begin{tabular}{|c|c|}
\hline Article History & Abstrak \\
\hline $\begin{array}{l}\text { Teori Terpadu } \\
\text { Penerimaan dan } \\
\text { Penggunaan Teknologi } \\
\text { (UTAUT 2), Intensi } \\
\text { Perilaku, Perilaku } \\
\text { Penggunaan, E-learning }\end{array}$ & $\begin{array}{l}\text { Penelitian ini bertujuan untuk memperoleh dan menganalisis bukti empiris } \\
\text { faktor-faktor yang mempengaruhi penerimaan dan penggunaan e-learning oleh } \\
\text { peserta didik pada jenjang SLTA dan Perguruan Tinggi di Tasikmalaya dengan } \\
\text { total subjek penelitian sebanyak } 289 \text { responden. Teknik analisis data dilakukan } \\
\text { dengan Partial Last Squares - Structural Equation Modeling (PLS - SEM) } \\
\text { melalui software SmartPLS versi 3.2.9. Berdasarkan hasil pengujian pada } \\
\text { sampel siswa SLTA diketahui bahwa Social influence dan kebiasaan } \\
\text { berpengaruh positif terhadap Behavioral intention, adapun Use behavior e- } \\
\text { learning pada siswa SLTA secara signifikan dipengaruhi oleh Habit dan } \\
\text { Behavioral intention. Pengujian pada kelompok sampel mahasiswa } \\
\text { menunjukkan bahwa facilitating condition, hedonic motivation, dan habit } \\
\text { berpengaruh signifikan terhadap behavioral intention, adapun Use behavior e- } \\
\text { learning pada mahasiswa hanya dipengaruhi oleh Habit. Melalui penelitian ini } \\
\text { akan dapat diketahui faktor-faktor determinan yang mempengaruhi } \\
\text { penggunaan e-learning pada peserta didik. } \\
\text { Abstract }\end{array}$ \\
\hline
\end{tabular}

This study aims to obtain and analyze empirical evidence of the factors affecting the acceptance and use of e-learning by students at the high school and college students in Tasikmalaya with a total number are 289 research objects. The data analysis technique was done by using Partial Last Squares Structural Equation Modeling (PLS-SEM) through SmartPLS version 3.2.9 software. Based on the test results showed in a sample of high school students, it is known that social influence and Habit gave a positive effect on Behavioral intention, while the Use behavior of e-learning on high school students was significantly influenced by Habit and Behavioral intention. Then the Testing on a sample group of college students showed that facilitating conditions, hedonic motivation, and habits gave a significant effect on behavioral intention, while the use of e-learning behavior on students only influenced by Habit. Through this research, it will be able to know the determinant factors that affect the use of e-learning in students. 


\section{PENDAHULUAN}

Teknologi informasi dan komunikasi (TIK) telah banyak berperan dan berkontribusi dalam upaya menyelesaikan berbagai problematika yang dihadapi dalam sektor Pendidikan, terutama setelah Covid19 ditetapkan sebagai pandemi global oleh World Health Organization (WHO) dan pemerintah menginstruksikan agar sekolah ditutup sementara guna menekan penyebaran virus Covid-19. Pada kondisi demikian, TIK menduduki peran yang sangat penting dalam upaya menjaga pelaksanaan pembelajaran agar tetap berlangsung meskipun dilaksanakan pada situasi dan kondisi yang tidak lazim dan berbeda dari biasanya, hal ini sebagaimana prinsip dikemukakan oleh Zhang et al., (2020) bahwa "Suspending classes without stopping learning".

Jika diamati pada dasarnya wabah Covid-19 di Indonesia telah menjadi salah satu faktor pendorong perubahan ekstrim pada penggunaan TIK dalam proses pembelajaran di berbagai jenjang pendidikan. Di dalam hal ini, perubahan yang paling tampak dapat dilihat dari penggunaan pembelajaran jarak jauh (distance learning) yang menjadi satu-satunya alternatif yang dapat dilakukan (Chaeruman, 2020). Penggunaan TIK dalam proses pembelajaran terutama setelah Covid-19 tidak hanya dilakukan di Indonesia, namun dilakukan juga oleh berbagai negara di dunia, perbedaannya terletak pada penerimaan peserta didik dan masyarakat Indonesia yang cenderung belum terbiasa melakukan aktivitas pembelajaran melalui TIK.

Aktivitas pembelajaran jarak jauh atau dalam konteks yang lebih umum disebut dengan electronic learning (e-learning) tentunya juga telah berimplikasi pada semakin tergesernya metode pembelajaran tradisional oleh pembelajaran yang lebih berbasis teknologi digital (Witt \& Gloerfeld, 2018). Di dalam hal ini e-learning dimaknai sebagai pembelajaran yang menitikberatkan pada penggunaan perangkat elektronik dan internet untuk mengakses materi pembelajaran, berinteraksi dengan guru, atau pun juga dengan sesama peserta didik tanpa dibatasi oleh ruang dan waktu (Farahat, 2012; Salsabila, Abdurachman \& Marpaung, 2019; Yodha et al., 2019; Putra et al., 2020).

Di sisi lain, meskipun e-learning sebagai sebuah teknologi menjadi opsi terbaik untuk menjaga kesinambungan proses belajar mengajar di tengah pandemi Covid-19, namun perlu dipahami bahwa penggunaan e-learning belum tentu selalu diterima dengan baik sebagaimana peserta didik menerima pembelajaran secara konvensional. Bisa jadi peserta didik sebenarnya tidak terlalu menerima, tidak menyukai atau bahkan sebenarnya menolak e-learning (Brangier \& Adele, 2013; Recker, 2016). Meskipun di dalam beberapa riset disebutkan bahwa penggunaan e-learning dapat meningkatkan hasil belajar siswa secara signifikan (Hoerunnisa et al., 2019; Prasistayanti et al., 2019; Rohimah et al., 2020), namun hasil penelitian tersebut belum dapat mengukur tingkat penerimaan dan penggunaan e-learning, terlebih pada masa wabah Covid-19.

Penelitian terkait penerimaan dan penggunaan e-learning merupakan hal yang penting, sebab secara umum sukses atau tidaknya penerapan sebuah teknologi termasuk e-learning akan sangat tergantung pada penerimaan dan penggunaan dari masing-masing individu, oleh karena itu perlu diselidiki faktor-faktor yang dapat mempengaruhi penerimaan dan penggunaan e-learning pada peserta didik. Penyelidikan terhadap faktor-faktor yang mempengaruhi penerimaan dan penggunaan teknologi termasuk di dalamnya $e$-learning, umumnya masih dilakukan dengan mengacu pada Theory Acceptance Model (TAM) yang dikembangkan oleh Davis et al., (1989), sebagaimana pernah dilakukan oleh Arianto et al., (2020).

Di dalam upaya mengisi gap permasalahan dalam menyelidiki faktor-faktor yang mempengaruhi penerimaan dan penggunaan e-learning, dalam penelitian ini penulis merujuk pada model yang mutakhir, yakni Unified Theory of Acceptance and Use of Technology 2 (UTAUT 2) yang digagas oleh Venkatesh et al., (2012). Melalui Unified Theory of Acceptance and Use of Technology 2 akan dapat diketahui bagaimana penerimaan dan penggunaan dari sudut pandang peserta didik sebagai konsumen pengguna teknologi e-learning. Model UTAUT 2 merupakan sebuah model yang dikembangkan untuk secara efektif memprediksi, menjelaskan dan menganalisis perilaku penerimaan teknologi masyarakat untuk produk teknologi informasi.

Terkait dengan penggunaan UTAUT 2 untuk mengetahui penerimaan dan penggunaan e-learning, peneliti tidak memasukkan konstruk Price value ke dalam model yang akan diteliti dengan asumsi 
bahwa subjek penelitian telah memiliki media elektronik sehingga tidak memerlukan biaya untuk membeli perangkat elektronik tambahan, oleh sebab itu peneliti hanya menggunakan delapan variabel dengan enam variabel eksogen, dua variabel endogen, dan jenjang pendidikan sebagai variabel kontrol.

Variabel eksogen terdiri dari harapan kinerja (performance expectancy) merujuk pada kepercayaan seseorang mengenai keuntungan kinerja yang akan didapatkan ketika menggunakan teknologi, harapan usaha (effort expectancy) merujuk pada tingkat kemudahan penggunaan teknologi, pengaruh sosial (social influence) merujuk pada sugesti yang diberikan orang lain untuk menggunakan teknologi, kondisi fasilitas (facilitating condition) merujuk pada persepsi bahwa adanya fasilitas yang memadai untuk menggunakan teknologi, motivasi hedonis (hedonic motivation) merujuk pada kesenangan yang didapatkan dari penggunaan teknologi, dan kebiasaan (habit) merujuk pada kecenderungan individu menggunakan teknologi secara otomatis. Variabel endogen terdiri dari niat perilaku (behavioral intention) yang merujuk pada niat untuk menggunakan teknologi dan perilaku penggunaan (use behavior) merujuk pada pola penggunaan teknologi.

Tujuan penelitian ini adalah untuk menyelidiki faktor determinan penerimaan dan penggunaan yang akan berimplikasi pada formula yang tepat dalam mensukseskan penerapan e-learning pada jenjang Pendidikan SLTA dan Perguruan Tinggi.

\section{METODE}

Penelitian ini dilakukan dengan menggunakan pendekatan kuantitatif dengan jenis penelitian eksplanatori (explanatory research) yaitu penelitian yang dilakukan untuk menguji hipotesis dan teori yang menjelaskan bagaimana dan mengapa suatu fenomena terjadi (Johnson \& Christensen, 2017). Penelitian ini dilakukan terhadap 289 subjek peserta didik dari jenjang SLTA dan Perguruan Tinggi di Tasikmalaya dengan 147 orang siswa SLTA dan 142 orang mahasiswa yang didapatkan berdasarkan teknik purposive sampling.

Secara umum, kedua kelompok sampel berada satu wilayah, yakni Kota Tasikmalaya, adapun perbedaan di antara kedua kelompok sampel terletak pada tingkat usia dan pemahaman berikut perlengkapan untuk menggunakan TIK dalam konteks pembelajaran, di mana kelompok mahasiswa cenderung memiliki pemahaman dan perlengkapan yang lebih memadai dan relatif berusia lebih tua dibanding sampel siswa.

Data dikumpulkan pada akhir bulan Juni hingga Juli atau tepatnya setelah aktivitas sekolah ditutup sementara dan pembelajaran mulai dilakukan secara online menggunakan berbagai media yang telah ditentukan oleh lembaga pendidikannya masing-masing. Pengumpulan data dilakukan melalui kuesioner yang diadaptasi dari Venkatesh et al., (2012), terdiri dari 30 item pertanyaan dengan skala numerik tujuh poin yang disebar melalui fasilitas google form .

\section{Analisis Data}

Setelah data terkumpul selanjutnya dilakukan analisis data dengan menggunakan metode Structural Equation Modeling berbasis Partial Last Square (SEM-PLS) dengan multigrup sampel yang dianalisis secara terpisah (losse cross-validation) menggunakan software SmartPLS 3.3.2. Analisis multigrup sampel dilakukan apabila melibatkan variabel moderator atau kontrol untuk tujuan komparasi analisis data berdasarkan karakteristik sampel dengan dua atau lebih data set (Ghozali \& Latan, 2015; Kusnendi, 2008). Analisis multigrup ini dilakukan karena adanya variabel kontrol yang berbentuk kategori, sehingga tidak dapat menggunakan analisis efek interaksi yang dikhususkan untuk variabel berbentuk metrik laten. Pengujian dalam SEM-PLS dilakukan melalui dua model sub struktur yaitu model pengukuran (outer model) dan model struktural (inner model). Selanjutnya untuk mengetahui pengaruh antar variabel, maka dilakukan prosedur Bootsraping terhadap data dan sampel yang digunakan, adapun untuk mengetahui perbedaan di antara kedua grup sampel, digunakan pendekatan parametrik dengan formula yang disarankan oleh Chin (2000) yaitu Smith-Satterhwaite Test. 


\section{HASIL}

\section{Evaluasi Model Pengukuran PLS-SEM}

Evaluasi model dalam Structural Equation Modelling terdiri dari dua tahap, yaitu evaluasi model pengukuran dan evaluasi model struktural. Evaluasi model pengukuran dilakukan untuk memvalidasi model penelitian dengan mengacu pada dua parameter yaitu validitas yang mengacu pada koefisien validitas konvergen dan validitas diskriminan, adapun reliabilitas konstruk mengacu pada koefisien reliabilitas komposit.

Hasil uji validitas konvergen pada dua kelompok sampel disajikan dalam Tabel 1.

Tabel 1. Validitas Konvergen Pada Kedua Kelompok Sampel

\begin{tabular}{|c|c|c|c|c|c|c|}
\hline & \multicolumn{3}{|c|}{ Sampel SLTA } & \multicolumn{3}{|c|}{ Sampel Mahasiswa } \\
\hline & Model & Model & Model & Model & Model & Model \\
\hline & Pengukuran & Respresifikasi 1 & Respesifikasi 2 & Pengukuran & Respesifikasi 1 & Respesifikasi 2 \\
\hline PE1 & 0,822 & 0,855 & 0,862 & 0,811 & 0,825 & 0,825 \\
\hline PE2 & 0,629 & & & 0,647 & & \\
\hline PE3 & 0,818 & 0,867 & 0,869 & 0,780 & 0,795 & 0,795 \\
\hline PE4 & 0,713 & 0,738 & 0,726 & 0,713 & 0,746 & 0,747 \\
\hline PE5 & 0,695 & & & 0,715 & 0,703 & 0,703 \\
\hline EE1 & 0,848 & 0,861 & 0,853 & 0,792 & 1,000 & 1,000 \\
\hline EE2 & 0,272 & & & 0,654 & & \\
\hline EE3 & 0,869 & 0,875 & 0,882 & 0,602 & & \\
\hline SI1 & 0,739 & 0,690 & & 0,466 & & \\
\hline SI2 & 0,693 & & & 0,738 & 0,760 & 0,761 \\
\hline SI3 & 0,839 & 0,899 & 1,000 & 0,897 & 0,901 & 0,900 \\
\hline $\mathrm{FC1}$ & 0,621 & & & 0,610 & & \\
\hline FC2 & 0,828 & 0,942 & 0,841 & 0,738 & 0,823 & 0,823 \\
\hline FC3 & 0,735 & 0,849 & 0,841 & 0,628 & & \\
\hline FC4 & 0,681 & & & 0,579 & & \\
\hline FC5 & 0,651 & & & 0,760 & 0,882 & 0,882 \\
\hline FC6 & 0,612 & & & 0,630 & & \\
\hline HM1 & 0,916 & 0,916 & 0,910 & 0,894 & 0,871 & 0,871 \\
\hline HM2 & 0,915 & 0,915 & 0,913 & 0,928 & 0,909 & 0,909 \\
\hline HM3 & 0,825 & 0,825 & 0,833 & 0,836 & 0,871 & 0,871 \\
\hline HB1 & 0,752 & 0,749 & 0,738 & 0,778 & 0,690 & \\
\hline HB2 & 0,779 & 0,773 & 0,761 & 0,692 & & \\
\hline HB3 & 0,866 & 0,871 & 0,885 & 0,766 & 0,903 & 1,000 \\
\hline BI1 & 0,702 & 0,692 & & 0,571 & & \\
\hline BI2 & 0,845 & 0,849 & 0,903 & 0,720 & 0,850 & 0,852 \\
\hline $\mathrm{BI} 3$ & 0,847 & 0,852 & 0,888 & 0,767 & 0,784 & 0,782 \\
\hline UB1 & 0,654 & & & 0,778 & 0,841 & 0,853 \\
\hline UB2 & 0,785 & 0,869 & 0,870 & 0,719 & 0,837 & 0,824 \\
\hline UB3 & 0,619 & & & 0,470 & & \\
\hline UB4 & 0,810 & 0,890 & 0,889 & 0,662 & & \\
\hline
\end{tabular}

Keterangan: sel yang diarsir menandakan indikator yang tidak valid dan harus dibuang.

PE : Performance Expectancy

EE : Effort Expectancy

SI : Social influence

FC : Facilitating Condition

HM : Hedonic Motivation

HB : Habit

BI : Behavioral Intention

UB : Use Behavior 
Berdasarkan hasil pengujian evaluasi model pengukuran pada kelompok sampel siswa SLTA diketahui bahwa terdapat 10 indikator yang tidak memenuhi rule of thumb yang ditetapkan dalam mengukur validitas konvergen, yakni $>0,70$. Indikator-indikator yang tidak valid tersebut tidak boleh digunakan di dalam penelitian (Jarvis et al., 2003), sehingga 10 indikator tersebut dibuang dari model pengukuran dan dilakukan uji model pengukuran respesifikasi.

Pengujian model pengukuran respesikasi ke-1 menunjukkan bahwa masih ada dua indikator yang tidak valid, sehingga kedua indikator tersebut dibuang dan kembali dilakukan uji model pengukuran respesifikasi ke-2, sehingga total ada 12 indikator yang dibuang dan tersisa 18 indikator yang memenuhi kriteria rule of thumb $>0,70$ untuk digunakan.

Pengujian model pengukuran pada kelompok sampel mahasiswa menunjukkan bahwa terdapat 12 indikator yang tidak valid, sehingga ke-12 indikator tersebut dibuang dan kembali dilakukan uji model pengukuran respesifikasi ke-1. Pada pengujian model respesifikasi yang kedua, masih didapatkan satu indikator yang tidak valid, sehingga dilakukan pembuangan indikator, sampai tersisa 17 indikator yang valid $(>0,70)$.

Validitas diskriminan untuk kelompok sampel siswa SLTA dan Mahasiswa berdasarkan model respesifikasi kedua yang diketahui melalui kriteria Fornell-Larcker menunjukkan bahwa nilai akar Average Varian Extracted (AVE) masing-masing model pengukuran menunjukkan lebih besar daripada nilai korelasi variabel laten, hal tersebut mengindikasikan bahwa indikator yang digunakan memiliki validitas diskriminan yang memadai. Tingkat konsisten internal dilihat melalui koefisien reliabilitas komposit dengan rule of thumb sebuah konstruk dikatakan reliabel apabila memiliki koefisien $>0,70$. Koefisien reliabilitas komposit pada grup sampel siswa SLTA dan mahasiswa dapat dilihat pada Tabel 2 .

Tabel 2. Reliabilitas Konstruk Pada Kedua Kelompok Sampel

\begin{tabular}{lcc}
\hline \multirow{2}{*}{ Konstruk } & \multicolumn{2}{c}{ Reliabilitas Komposit } \\
\cline { 2 - 3 } & Grup SLTA & Grup mahasiswa \\
\hline Behavioral intention & 0,890 & 0,801 \\
\hline Effort Expectancy & 0,859 & 1,000 \\
\hline Facilitating condition & 0,889 & 0,842 \\
\hline Habit & 0,839 & 1,000 \\
\hline Hdonic Motivation & 0,916 & 0,914 \\
\hline Performance Expectancy & 0,861 & 0,852 \\
\hline Social influence & 1,000 & 0,819 \\
\hline Use Behavior & 0,873 & 0,826 \\
\hline
\end{tabular}

Berdasarkan perhitungan dari model respesifikasi kedua diketahui bahwa reliabilitas komposit pada pada grup sampel siswa SLTA dan mahasiswa diketahui berada di atas 0,70. Hal ini mengindikasikan bahwa seluruh konstruk pada kedua kelompok sampel memiliki reliabilitas yang memadai.

\section{Evaluasi Model Struktural PLS-SEM}

Hasil evaluasi model struktural diperoleh dari nilai $\mathrm{R}^{2}$ model respesifikasi kedua untuk masingmasing grup. Nilai $\mathrm{R}^{2}$ disajikan dalam Tabel 3 . 
Tabel 3. Nilai $\mathbf{R}^{2}$ Pada Kedua Kelompok Sampel

\begin{tabular}{lcc}
\hline \multirow{2}{*}{ Variabel endogen } & \multicolumn{2}{c}{ Grup sampel } \\
\cline { 2 - 3 } & SLTA & Mahasiswa \\
\hline Behavioral intenton & 0,439 & 0,329 \\
\hline Use behavior & 0,385 & 0,394 \\
\hline
\end{tabular}

Merujuk pada Tabel 3, nilai $\mathrm{R}^{2}$ untuk kelompok sampel siswa SLTA berarti bahwa kontribusi yang diberikan oleh variabel Performance Expectancy, Effort Expectancy, Social Influence, Facilitating Condition, Hedonic Motivation, dan Habit terhadap Behavioral Intention pada kelompok siswa SLTA sebesar $43,9 \%$ atau termasuk dalam kategori moderat, adapun sisanya sebesar 56,1\% dijelaskan oleh variabel lain yang tidak diteliti.

Nilai $\mathrm{R}^{2}$ untuk Use Behavior sebesar 0,385, berarti bahwa kontribusi yang diberikan Performance Expectancy, Effort Expectancy, Social Influence, Facilitating Condition, Hedonic Motivation, Habit, dan Behavioral Intention terhadap Use Behavior pada siswa SLTA adalah sebesar 38,5\% atau dalam kategori moderat, sedangkan sisanya sebesar $61,5 \%$ dipengaruhi oleh variabel lain. Nilai $\mathrm{R}^{2}$ untuk grup sampel mahasiswa mencapai 0,329 untuk Behavioral Intention yang berarti bahwa sebesar 32,9\% atau secara moderat Behavioral Intention pada sampel mahasiswa dipengaruhi oleh Performance Expectancy, Effort Expectancy, Social Influence, Facilitating Condition, Hedonic Motivation, dan Habit, adapun sebesar 67,1\% dipengaruhi oleh variabel lain yang tidak diteliti.

Di samping itu, nilai $\mathrm{R}^{2}$ untuk Use Behavior sebesar 0,394 yang berarti bahwa 39,4\% Use Behavior pada sampel mahasiswa dipengaruhi oleh Performance Expectancy, Effort Expectancy, Social Influence, Facilitating Condition, Hedonic Motivation, Habit, dan Behavioral Intention, adapun 60,6\% dipengaruhi oleh variabel yang tidak diteliti.

\section{Uji Hipotesis}

Uji hipotesis dilihat melalui prosedur bootstrapping, adapun hasilnya disajikan dalam Tabel 4. Hasil pengujian dalam taraf signifikansi 5\% dengan kaidah pengujian coefficient path dinilai signifikan apabila nilai t-statistik lebih besar dari 1,96 (Hair, Ringle \& Sarstedt, 2011).

Tabel 4. Signifikansi Model Struktural Grup Sampel siswa SLTA

\begin{tabular}{|c|c|c|c|c|c|}
\hline & Koefisien Path & $\mathbf{f}^{2}$ & Std. Error & $\mathbf{t}$ & p-value \\
\hline \multirow{2}{*}{$\mathrm{PE} \rightarrow \mathrm{BI}$} & $-0,041$ & 0,001 & 0,092 & 0,451 & 0,326 \\
\hline & 0,006 & 0,000 & 0,099 & 0,062 & 0,475 \\
\hline \multirow{2}{*}{$\mathrm{EE} \rightarrow \mathrm{BI}$} & 0,112 & 0,011 & 0,093 & 1,200 & 0,115 \\
\hline & 0,064 & 0,003 & 0,092 & 0,693 & 0,244 \\
\hline \multirow{2}{*}{$\mathrm{SI} \rightarrow \mathrm{BI}$} & 0,277 & 0,108 & 0,076 & 3,639 & 0,000 \\
\hline & 0,069 & 0,006 & 0,079 & 0,875 & 0,191 \\
\hline \multirow{2}{*}{$\mathrm{FC} \rightarrow \mathrm{BI}$} & 0,106 & 0,013 & 0,098 & 1,081 & 0,140 \\
\hline & 0,203 & 0,038 & 0,097 & 2,102 & 0,018 \\
\hline \multirow{2}{*}{$\mathrm{HM} \rightarrow \mathrm{BI}$} & $-0,147$ & 0,015 & 0,122 & 1,199 & 0,115 \\
\hline & 0,248 & 0,049 & 0,104 & 2,378 & 0,009 \\
\hline \multirow{2}{*}{$\mathrm{HB} \rightarrow \mathrm{BI}$} & 0,489 & 0,163 & 0,111 & 4,390 & 0,000 \\
\hline & 0,225 & 0,068 & 0,090 & 2,503 & 0,006 \\
\hline \multirow{2}{*}{$\mathrm{FC} \rightarrow \mathrm{UB}$} & 0,058 & 0,004 & 0,106 & 0,545 & 0,293 \\
\hline & 0,062 & 0,005 & 0,082 & 0,757 & 0,225 \\
\hline \multirow{2}{*}{$\mathrm{HB} \rightarrow \mathrm{UB}$} & 0,349 & 0,111 & 0,084 & 4,172 & 0,000 \\
\hline & 0,545 & 0,414 & 0,065 & 8,355 & 0,000 \\
\hline \multirow{2}{*}{$\mathrm{BI} \rightarrow \mathrm{UB}$} & 0,310 & 0,099 & 0,097 & 3,202 & 0,001 \\
\hline & 0,128 & 0,020 & 0,078 & 1,635 & 0,051 \\
\hline
\end{tabular}


Merujuk Tabel 4 diketahui bahwa pada sampel siswa SLTA hanya terdapat empat hubungan variabel yang memiliki nilai t-statistik $>1,96$. Hal tersebut menjadi indikasi bahwa keempat hubungan variabel $\mathrm{SI} \rightarrow \mathrm{BI}, \mathrm{HB} \rightarrow \mathrm{BI}, \mathrm{HB} \rightarrow \mathrm{UB}$, dan $\mathrm{BI} \rightarrow \mathrm{UB}$ adalah signifikan. Adapun kelima hubungan variabel sisanya merupakan hubungan yang tidak signifikan ( $\mathrm{t}$-statistik $<1,96)$. Adapun dalam kelompok sampel mahasiswa diketahui hanya terdapat empat hubungan variabel yang signifikan ( $\mathrm{t}$ statistik $>1,96$ ), yaitu FC $\rightarrow$ BI, $\mathrm{HM} \rightarrow \mathrm{BI}, \mathrm{HB} \rightarrow \mathrm{BI}$, dan $\mathrm{HB} \rightarrow \mathrm{UB}$, adapun lima hubungan antar variabel sisanya tidak signifikan (t-statistik $<1,96)$.

Uji perbandingan antar grup sampel dilakukan untuk mengetahui adanya perbedaan pengaruh $\mathrm{HB}$ terhadap BI dan UB dalam kedua grup sampel, maka dilakukan proses pengujian menggunakan SmithSatterhwaite Test dengan hasil pengujian tersaji dalam Tabel 5.

Tabel 5. Hasil Uji Smith-Satterhwaite Test

\begin{tabular}{cccccc}
\hline \multirow{2}{*}{ Hubungan } & \multicolumn{2}{c}{ SLTA } & \multicolumn{2}{c}{ Mahasiswa } & \multirow{2}{*}{ Nilai t } \\
\cline { 2 - 5 } & Koefisien Path & Std. Error & Koefisien Path & Std. Error & \\
\hline HB $\rightarrow$ BI & 0,163 & 0,095 & 0,225 & 0,090 & 0,47 \\
\hline HB $\rightarrow$ UB & 0,111 & 0,062 & 0,545 & 0,065 & 4,83 \\
\hline
\end{tabular}

Berdasarkan pada hasil Smith-Satterhwaite Test sebagaimana tersaji dalam Tabel 5, diketahui bahwa pada hubungan HB terhadap BI pada kedua sampel grup tidak terdapat perbedaan signifikan karena nilai t-statistik lebih kecil dari pada t-tabel dengan taraf signifikansi 5\% yaitu 1,96 $(0,47<1,96)$, adapun pada hubungan HB $\rightarrow$ UB pada kedua sampel terdapat perbedaan signifikan, hal ini merujuk pada nilai t-statistik yang lebih besar daripada nilai t-tabel $(4,83>1,96)$.

\section{PEMBAHASAN}

\section{Pengaruh Performance expectancy terhadap Behavioral intention e-learning}

Di dalam Tabel 4 dan 5, diketahui bahwa nilai t-statistik untuk pengaruh PE terhadap BI pada masing-masing grup lebih kecil dari 1,96 (0,041 dan 0,061), hal tersebut mengindikasikan bahwa pada grup sampel SLTA dan grup sampel mahasiswa, Performance Expectancy tidak memberikan pengaruh yang signifikan terhadap Behavioral Intention. Temuan ini seperti dikemukakan hasil penelitian yang dilakukan oleh Sutanto, Ghozali \& Handayani (2018), namun bertentangan dengan penelitan yang dilakukan oleh (Nguyen, Nguyen \& Cao (2014); Merhi (2015); Chu \& Chen (2016); El-Masri \& Tarhini, (2017) yang menyatakan bahwa Performance Expectancy menjadi prediktor paling berpengaruh dari Behavioral Intention.

Pengaruh yang tidak signifikan tersebut diduga karena peserta didik baik siswa atau mahasiswa belum sepenuhnya meyakini bahwa penggunaan e-learning dapat memberi keuntungan dalam efektivitas pembelajaran ketika pembelajaran di sekolah dihentikan, hal ini diperkuat data terbaru yang menyatakan bahwa 69 juta siswa Indonesia berpotensi kehilangan program belajar (Arsendy et al., 2020).

Bagi negara berkembang, khususnya di Indonesia minimnya pemahaman mengenai penggunaan serta manfaat e-learning masih dapat dimaklumi, mengingat penggunaan e-learning sebelum mewabahnya Covid-19 masih relatif jarang. Selain itu, infrastruktur yang menunjang penggunaan $e-$ learning pun masih belum merata, hal ini diperkuat oleh laporan penelitian yang menyatakan bahwa hanya $40 \%$ orang Indonesia yang memiliki akses internet untuk menunjang e-learning (Arsendy et al., 2020).

Di samping itu, apabila diamati dengan saksama kampanye dan penggunaan e-learning yang baru dilakukan secara masif setelah adanya Covid-19 membuat pelajar Indonesia sedikit kaget dengan kebijakan baru sehingga penggunaan e-learning lebih didorong karena faktor situasi dan kondisi 
sehingga masih banyak kalangan menganggap e-learning sebagai aktivitas pembelajaran yang menjenuhkan dan tidak efektif.

\section{Pengaruh Effort expectancy terhadap Behavioral intention e-learning}

Di dalam Tabel 4 dan 5, diketahui bahwa nilai t-statistik untuk pengaruh PE terhadap BI pada masing-masing grup lebih kecil dari 1,96 (0,041 dan 0,061), hal tersebut mengindikasikan bahwa pada grup sampel SLTA dan grup sampel mahasiswa, Performance Expectancy tidak memberikan pengaruh yang signifikan terhadap Behavioral Intention. Temuan ini seperti dikemukakan hasil penelitian yang dilakukan oleh Sutanto, Ghozali \& Handayani (2018), namun bertentangan dengan penelitian yang dilakukan oleh (Nguyen, Nguyen \& Cao (2014); Merhi (2015); Chu \& Chen (2016); El-Masri \& Tarhini, (2017) yang menyatakan bahwa Performance Expectancy menjadi prediktor paling berpengaruh dari Behavioral Intention.

Pengaruh yang tidak signifikan tersebut diduga karena peserta didik baik siswa atau mahasiswa belum sepenuhnya meyakini bahwa penggunaan e-learning dapat memberi keuntungan dalam efektivitas pembelajaran ketika pembelajaran di sekolah dihentikan, hal ini diperkuat data terbaru yang menyatakan bahwa 69 juta siswa Indonesia berpotensi kehilangan program belajar (Arsendy et al., 2020).

Bagi negara berkembang, khususnya di Indonesia minimnya pemahaman mengenai penggunaan serta manfaat e-learning masih dapat dimaklumi, mengingat penggunaan e-learning sebelum mewabahnya Covid-19 masih relatif jarang. Selain itu, infrastruktur yang menunjang penggunaan $e-$ learning pun masih belum merata, hal ini diperkuat oleh laporan penelitian yang menyatakan bahwa hanya $40 \%$ orang Indonesia yang memiliki akses internet untuk menunjang e-learning (Arsendy et al., 2020).

\section{Pengaruh Social Influence terhadap Behavioral intention e-learning}

Pengaruh Social Influence terhadap Behavioral Intention menunjukkan hubungan yang signifikan untuk sampel grup siswa SLTA $(3,639>1,96)$ dengan tingkat effect size $\left(\mathrm{f}^{2}\right)$ sebesar 0,108 atau dalam kategori rendah. Di samping itu, pengaruh Social Influence terhadap Behavioral Intention pada sampel mahasiswa tidak signifikan $(0,879<1,96)$. Penjelasan yang paling logis mengenai hasil yang berbeda ini kemungkinan terkait dengan sikap subjek penelitian terhadap pengaruh sosial di sekitarnya. Patut diduga siswa SLTA memiliki sikap yang lebih sensitif terhadap pengaruh sosial di sekitarnya, adapun mahasiswa relatif independen dalam mengambil keputusan.

Kendati demikian, dugaan tersebut di atas juga perlu diteliti lebih lanjut, sebab pada dasarnya instruksi penggunaan e-learning dikeluarkan pemerintah pusat untuk seluruh jenjang Pendidikan termasuk SLTA dan perguruan tinggi, hal ini berarti seharusnya baik dan pada tingkat SLTA atau pada tingkat mahasiswa sama-sama memiliki pengaruh Social Influence yang sama dalam terbentuknya Behavioral Intention.

Secara empiris temuan terkait pengaruh Social Influence terhadap Behavioral Intention yang tidak signifikan pada level perguruan tinggi ini didukung oleh penelitian yang dilakukan oleh $\mathrm{Wu}$, Wang \& Lin (2007; Kumar \& Mohite (2017); Yakubu \& Dasuki (2018); Arain et al., (2019).

\section{Pengaruh Facilitating Condition terhadap Behavioral intention e-learning}

Pengaruh Facilitating Condition terhadap Behavioral Intention pada kedua kelompok sampel juga menunjukkan hasil yang berbeda. Pada kelompok sampel SLTA Facilitating Condition tidak memberikan pengaruh signifikan terhadap Behavioral Intention $(1,081<1,96)$. Adapun pengaruh pengaruh Facilitating Condition terhadap Behavioral Intention pada kelompok sampel mahasiswa menunjukkan hasil yang signifikan $(2,012>1,96)$ dengan effect size $\left(\mathrm{f}^{2}\right)$ sebesar 0,038 (rendah). 
Pengaruh signifikannya Facilitating Condition terhadap Behavioral Intention pada sampel mahasiswa diduga karena pada level perguruan tinggi fasilitas e-learning cukup memadai dan selain itu perguruan tinggi juga lebih memiliki kemampuan finansial yang kuat dibanding dengan lembaga pendidikan lain. Pada level SLTA diduga bahwa fasilitas e-learning masih belum memadai, terlebih bagi lembaga pendidikan yang berlokasi di daerah. Adanya fasilitas yang belum memadai ini cukup dapat dimaklumi, sebab e-learning di Indonesia dilaksanakan lebih karena kondisi darurat Covid-19, bukan karena perencanaan yang telah dipersiapkan matang.

Terkait dengan fasilitas, dalam hal ini pemerintah harus bergerak cepat untuk menyediakan fasilitas yang memadai dalam rangka menekan kesenjangan TIK sehingga akses internet bisa lebih mudah, andal, dan terjangkau oleh semua kalangan.

\section{Pengaruh Hedonic motivation terhadap Behavioral intention e-learning}

Pengaruh Hedonic Motivation terhadap Behavioral Intention juga menunjukkan hasil yang berbeda pada kedua sampel. Pada sampel SLTA, menunjukkan hasil yang tidak signifikan $(1,199<1,96)$, sebaliknya pada sampel mahasiswa hedonic motivation berpengaruh signifikan terhadap behavioral intention $(2,378>1,96)$ dengan effect size $\left(\mathrm{f}^{2}\right)$ sebesar 0,049 .

Hedonic Motivation pada siswa SLTA tidak berpengaruh pada Behavioral Intention diduga karena siswa SLTA belum memiliki pengalaman yang memadai dalam menggunakan e-learning sehingga siswa SLTA belum memiliki motivasi yang dapat memicu penggunaan e-learning. Temuan pada sampel SLTA ini didukung oleh hasil penelitian dari Ain, Kaur \& Waheed (2016).

Pada kelompok sampel mahasiswa, Hedonic Motivation berpengaruh pada Behavioral Intention diyakini karena mahasiswa telah mencapai tingkat motivasi intrinsik yang dapat diterima ketika menggunakan e-learning. Terkait dengan hal tersebut, El-Masri \& Tarhini (2017) menyarankan agar para pengajar dapat menyisipkan fitur-fitur yang dapat meningkatkan kesenangan agar pelajar semakin menikmati aktivitas pembelajaran melalui e-learning.

\section{Pengaruh Habit terhadap Behavioral intention e-learning}

Pengaruh Habit terhadap Behavioral Intention pada kedua sampel menunjukkan hasil yang signifikan dengan masing-masing effect size ( $\left.\mathrm{f}^{2}\right)$ sebesar 0,163 (moderat) dan sebesar 0,068 (rendah) untuk sampel mahasiswa. Temuan ini konsisten dengan hasil penelitian yang dilakukan oleh Venkatesh, Thong \& Xu (2012); Lewis et al., (2013); El-Masri \& Tarhini (2017); Mehta et al., (2019); Gunasinghe et al., (2020).

Temuan mengenai pengaruh Habit terhadap Behavioral Intention ini mengindikasikan bahwa ketika peserta didik memiliki kebiasaan yang baik, maka intensi peserta didik dalam menggunakan $e$ learning pun akan semakin membaik, hal ini karena pada dasarnya Habit atau kebiasaan merupakan prediktor paling penting dalam membentuk intensi (Arain et al., 2019).

\section{Pengaruh Facilitating Condition terhadap Use Behavior e-learning}

Pengaruh Facilitating Condition terhadap Use Behavior pada dua kelompok sampel menunjukkan hasil yang tidak signifikan dengan t-statistik pada sampel SLTA dan mahasiswa sama-sama kurang dari 1,96. Temuan ini bertentangan dengan penelitian yang dilakukan oleh Agudo-peregrina, Hernándezgarcía \& Pascual-miguel (2014); Attuquayefio \& Addo (2014); Ameri et al., (2019); Gunasinghe et al., (2020).

Bagi negara berkembang seperti Indonesia, temuan ini cukup masuk akal sebab e-learning belum sepenuhnya menjadi kebiasaan mengingat distribusi sarana dan prasarana yang menunjang e-learning seperti kepemilikan perangkat digital dan jaringan internet sendiri masih belum merata. 


\section{Pengaruh Habit terhadap Use Bahavioral e-learning}

Pengaruh Habit terhadap Use Behavior pada kedua kelompok sampel menunjukkan hasil yang signifikan dengan nilai t-statistik lebih besar dari 1,96 (SLTA: 4,172; mahasiswa 8,355), dengan nilai effect size $\left(\mathrm{f}^{2}\right)$ sebesar 0,111 (rendah) untuk sampel SLTA, dan kategori tinggi $(0,414)$ untuk sampel mahasiswa. Berdasarkan koefisien $\mathrm{f}^{2}$, diketahui bahwa dalam penelitian ini Habit menjadi prediktor terkuat dalam memprediksi Use Bahavior pada subjek mahasiswa, temuan ini dapat dibuktikan dengan nilai $\mathrm{f}^{2}$ yang lebih besar dari yang lainnya.

Temuan ini konsisten dengan temuan dari Venkatesh, Thong and Xu, (2012); Harsono \& Suryana (2014). Hal ini berarti bahwa semakin tinggi Habit penggunaan e-learning, maka perilaku penggunaan e-learning pun akan meningkat. Di sisi lain, hasil penelitian ini menolak hasil penelitian dari Ain, Kaur \& Waheed (2016) mengemukakan bahwa Habit tidak memberikan pengaruh signifikan terhadap Use Behavior.

Terlepas dari awal penggunaan e-learning di Indonesia yang pada awalnya lebih didorong faktor Covid-19, jika merujuk pada temuan penelitian ini maka seharusnya semakin terbiasa pelajar dengan $e$ learning maka akan semakin baik pula perilaku penggunaan e-learning peserta didik asal didukung dengan adanya kondisi fasilitas yang memadai.

\section{Pengaruh Behavioral Intention terhadap Use Behavior e-learning}

Pengaruh Behavioral Intention terhadap Use Behavioral menjadi temuan paling menarik di mana hasil analisis data pada kedua sampel menunjukkan temuan yang berbeda. Pada kelompok sampel SLTA hasilnya menunjukkan pengaruh yang signifikan $(3,202>1,96)$ dengan nilai effect size $\left(\mathrm{f}^{2}\right)$ sebesar 0,099 (rendah, adapun pada kelompok sampel mahasiswa hasilnya menunjukkan hasil yang tidak signifikan $(1,635<1,96)$.

Temuan dalam kelompok sampel SLTA konsisten dengan banyak penelitian, di antaranya penelitian dari Dwivedi et al., (2017); Salloum \& Shaalan (2018). Selain itu, temuan ini juga mendukung Theory Reasoned Action (TRA), Theory Planned Behavior yang mengemukakan bahwa intensi merupakan prediktor terkuat dari perilaku (Fishbein \& Ajzen, 1975; Shimp \& Kavas, 1984; Ajzen, 1991), dan juga mendukung Unified Theory of Acceptance, and Use of Technology 2 (UTAUT 2) yang dikemukakan oleh Venkatesh et al., (2003); Venkatesh, Thong and Xu (2012).

Temuan menariknya adalah hasil yang didapat dari kelompok sampel mahasiswa, di mana hasil analisis data menunjukkan bahwa Behavioral Intention tidak memberikan pengaruh signifikan pada Use Behavior. Temuan pada kelompok sampel mahasiswa ini tentu menyelisihi temuan dari hasil penelitian empiris terdahulu yang menyatakan bahwa intensi merupakan prediktor terkuat dari sebuah perilaku. Temuan ini didukung oleh penelitian dari Agudo-peregrina, Hernández-garcía and Pascual-miguel (2014), namun demikian belum ada penjelasan rinci mengenai tidak signifikannya hubungan Bahavioral Intention terhadap Behavioral Use.

Di samping itu, apabila diamati dengan saksama kampanye dan penggunaan e-learning yang baru dilakukan secara masif setelah adanya Covid-19 membuat pelajar Indonesia sedikit kaget dengan kebijakan baru sehingga penggunaan e-learning lebih didorong karena faktor situasi dan kondisi sehingga masih banyak kalangan menganggap e-learning sebagai aktivitas pembelajaran yang menjenuhkan dan tidak efektif.

\section{SIMPULAN}

Merujuk pada temuan penelitian pada dua kelompok sampel, diketahui bahwa Behavioral Intention dan Use Behavior pada kelompok sampel SLTA dan Mahasiswa dipengaruhi oleh faktor-faktor yang berbeda, oleh sebab itu diharapkan agar tenaga pendidik lebih memperhatikan prediktor yang dapat 
memicu peserta didik agar memiliki behavioral intention dan use behavior e-learning dengan merujuk pada faktor-faktor yang mempengaruhi keduanya dalam konteks siswa dan mahasiswa.

Berdasarkan temuan empiris penelitian ini, Use Bahavior e-learning pada siswa SLTA lebih dipengaruhi oleh Behavioral Intention dan Habit, adapun Behavioral Intention dipengaruhi oleh Habit dan juga Social Influence dengan prediktor paling kuat yang mempengaruhi Behavioral Intention adalah Habit. Pada sampel mahasiswa Behavioral Intention dipengaruhi Facilitating Condition, Hedonic Motivation, dan Habit, sementara itu Use Bahavior e-learning hanya dipengaruhi oleh Habit saja. Pada kelompok sampel ini juga diketahui bahwa Habit menjadi prediktor yang memberikan pengaruh paling kuat terhadap Use Behavior e-learning. Kendati ada beberapa temuan yang tidak konsisten dengan penelitian model UTAUT 2 sebelumnya, namun inkonsistensi temuan tersebut dapat dimaklumi sebab pada dasarnya model UTAUT 2 dikembangkan dengan menggunakan sampel negara maju yang cenderung memiliki perbedaan budaya dengan negara berkembang seperti Indonesia.

\section{DAFTAR RUJUKAN}

Agudo-peregrina, Á. F., Hernández-garcía, Á., \& Pascual-miguel, F. J. (2014). Computers in Human Behavior Behavioral Intention, Use Behavior and The Acceptance of Electronic Learning Systems: Differences Between Higher Education and Lifelong Learning. Computers and Human Behavior, 34, 301-314. https://doi.org/10.1016/j.chb.2013.10.035

Ain, N. U., Kaur, K., \& Waheed, M. (2016). The influence of learning value on learning management system use: An extension of UTAUT2. Information Development, 32(5), 1306-1321. https://doi.org/10.1177/0266666915597546

Ajzen, I. (1991). The theory of planned behavior. Orgnizational Behavior and Human Decision Processes, 50, 179-211. https://doi.org/10.1016/0749-5978(91)90020-T

Ameri, A., Khajouei, R., Ameri, A., \& Jahani, Y. (2019). Acceptance of a mobile-based educational application (LabSafety) by pharmacy students: An application of the UTAUT2 model. Education and Information Technologies, 25, 419-435. https://doi.org/https://doi.org/10.1007/s10639-019-09965-5

Arain, A. A., Hussain, Z., Rizvi, W. H., \& Vighio, M. S. (2019). Extending UTAUT2 Toward Acceptance of Mobile Learning in The Context of Higher Education. Universal Access in the Information Society, 18(3), 659-673. https://doi.org/10.1007/s10209-019-00685-8

Arianto, F., Susarno, L. H., Dewi, U., \& Safitri, A. F. (2020). Model Penerimaan dan Pemanfaatan Teknologi Di Perguruan Tinggi. Jurnal Teknologi Pendidikan, 08(01), 110-121.

Arsendy, S., Gunawan, C. J., Rarasati, N., \& Suryadarma, D. (2020). Teaching and Learning During School Closure : Lessons from Indonesia (Nomor 89).

Attuquayefio, S. N., \& Addo, H. (2014). Using The UTAUT Model to Analyze Students' ICT Adoption. International Journal of Education Development Usiang Information and Communication Technology, $10(3), 75-86$.

Brangier, E., \& Adele, S. (2013). Evolutions in The Human Technology Relationship: Rejection, acceptance and Technosymbiosis. International Journal on WWW/ Internet, 11(3), 46-60.

Chaeruman, U. A. (2020). Ruang Belajar Baru dan Implikasi Terhadap Pembelajran di Era Tatanan Baru. Jurnal Teknologi Pendidikan, 08(01), 142-153. https://doi.org/http://dx.doi.org/10.31800/jtp.kw.v8n1.p142--153

Chin, W. W. (2000). Frequently Asked Questions - Partial Least Squares \& PLS - Graph. http://discnt.cba.uh.edu/chin/indx.html.

Chu, T. H., \& Chen, Y. Y. (2016). With Good We Become Good: Understanding e-learning adoption by theory of planned behavior and group influences. Computers and Education, 92-93, 37-52. https://doi.org/10.1016/j.compedu.2015.09.013

Davis, F. D., Bagozzi, R. P., \& Warshaw, P. R. (1989). User Acceptance of Computer Technology: A Comparison of Two Theoretical Models. Management Science, 35(8), 982-1003. https://doi.org/10.1287/mnsc.35.8.982

Dwivedi, Y. K., Rana, N. P., Jeyaraj, A., Clement, M., \& Williams, M. D. (2017). Re-examining the Unified Theory of Acceptance and Use of Technology ( UTAUT ): Towards a Revised Theoretical Model. Information Systems Frontiers, 21, 719-734. https://doi.org/10.1007/s10796-017-9774-y

El-Masri, M., \& Tarhini, A. (2017). Factors affecting the adoption of e-learning systems in Qatar and USA: Extending the Unified Theory of Acceptance and Use of Technology 2 (UTAUT2). Educational Technology 
Research and Development, 65, 743-763. https://doi.org/10.1007/s11423-016-9508-8

Farahat, T. (2012). Applying the Technology Acceptance Model to Online Learning in the Egyptian Universities. International Educationaal Technology Conference, 64, 95-104. https://doi.org/10.1016/j.sbspro.2012.11.012

Fishbein, M., \& Ajzen, I. (1975). Belief, Attitude, Intention and Behaviour: An Introduction to Theory and Research. Addison-Wesley Publishing.

Ghozali, I., \& Latan, H. (2015). Partial Last Squares: Konsep, Teknik, dan Aplikasi Menggunakan Program SmartPLS 3.0 (2 ed.). Badan Penerbit Undip.

Gunasinghe, A., Hamid, J. A., Khatibi, A., \& Azam, S. M. F. (2020). The Adequacy of UTAUT-3 in Interpreting Academician's Adoption to E-Learning in Higher Education Environments. Interactive Technology and Smart Education, 17(1), 86-106. https://doi.org/10.1108/ITSE-05-2019-0020

Hair, J. F., Ringle, C. M., \& Sarstedt, M. (2011). PLS-SEM: Indeed a silver bullet. Journal of Marketing Theory and Practice, 19(2), 139-152. https://doi.org/10.2753/MTP1069-6679190202

Harsono, L. D., \& Suryana, L. A. (2014). Factors Affecting the Use Behavior of Social Media Using UTAUT 2 Model. Proceedings of the First Asia-Pacific Conference on Global Business, Economics, Finance and Social Sciences (AP 14 Singapore Conference), August, 1-3.

Hoerunnisa, A., Suryani, N., \& Efendi, A. (2019). Efektivitas Penggunaan E-Learning pada Kelas Multimedia untuk Meningkatkan Prestasi dan Motivasi Belajar Siswa SMK. Jurnal Teknologi Pendidikan, 07(02), 123137.

Jarvis, C. B., Mackenzie, S. B., Podsakoff, P. M., Giliatt, N., \& Mee, J. F. (2003). A Critical Review of Construct Indicators and Measurement Model Misspecification in Marketing and Consumer Research. Journal of Consumer Research, 30(2), 199-218. https://doi.org/10.1086/376806

Johnson, B. R., \& Christensen, L. (2017). Educational Research: Quantitative, Qualitative, and Mixed Approaches (6 ed.). SAGE Publications, Inc.

Kumar, B. A., \& Mohite, P. (2017). Usability Study of Mobile Learning Application in Higher Education Context: An Example from Fiji National University. In A. Murphy, H. Farley, L. E. Dyson, \& H. Jones (Ed.), Mobile Learning in Higher Education in the Asia-Pacific Region: Harnessing Trends and Challenging Orthodoxies (Nomor July, hal. 607-622). Springer Nature Singapore. https://doi.org/10.1007/978-981-10-4944-6

Kusnendi, K. (2008). Model-Model Persamaan Strutural Satu dan Multigroup Sampel dengan LISREL. Alfabeta.

Lewis, C. C., Fretwell, C. E., Ryan, J., \& Parham, J. B. (2013). Faculty Use of Established and Emerging Technologies in Higher Education: A Unified Theory of Acceptance and Use of Technology Perspective. International Journal of Higher Education, 2(2), 22-34. https://doi.org/10.5430/ijhe.v2n2p22

Mehta, A., Morris, N. P., Swinnerton, B., \& Homer, M. (2019). The Influence of Values on E-learning Adoption. Computers and Education, 141. https://doi.org/10.1016/j.compedu.2019.103617

Merhi, M. I. (2015). Factors influencing higher education students to adopt podcast: An empirical study. Computers and Education, 83, 32-43. https://doi.org/10.1016/j.compedu.2014.12.014

Nguyen, T. D., Nguyen, D. T., \& Cao, T. H. (2014). Acceptance and use of information system: E-learning based on cloud computing in Vietnam. Information and Communication Technology, 8407(4960), 139-149. https://doi.org/10.1007/978-3-642-55032-4_14

Prasistayanti, N. W. N., Santyasa, W. I., \& Warpala, W. S. I. (2019). Pengaruh Desain E-Learning Terhadap Hasil Belajar dan Keterampilan Berpikir Kreatif Siswa dalam Mata Pelajaran Pemrograman pada Siswa SMK. Jurnal Teknologi Pendidikan, 07(02), 138-155.

Putra, R. D. Y. S., Susilaningsih, S., \& Abidin, Z. (2020). Pengembangan Media Website E-learning Berbasis Moel Responsive Web Design untuk Siswa SMA. Jurnal Kajian Teknologi Pendidikan, 3(3), $292-302$. https://doi.org/10.17977/um038v3i32020p292

Recker, J. (2016). Reasoning about Discontinuance of Information System Use. Journal of Information Technology Theory and Application, 17(1), 41-66.

Rohimah, R., Riswandi, R., \& Fitriawan, H. (2020). Pengembangan Media Pembelajaran Informatika Melalui ELearning untuk Meningkaykan Berpikir Kreatif Siswa. Jurnal KajianTeknologi Pendidikan, 3(3), 330-339. https://doi.org/10.17977/um038v3i32020p330

Salloum, S. A., \& Shaalan, K. (2018). Factors Affecting Students' Acceptance of E-Learning System in Higher Education Using UTAUT and Structural Equation Modeling Approaches. Proceedings of the International Conference on Advanced Intelligent Systems and Informatics 2018, 2, 469-480. https://doi.org/10.1007/9783-319-99010-1

Salsabila, Z., Abdurachman, E., \& Marpaung, S. H. (2019). Behavior Analysis of The Use of EE-learning using 
UTAUT Model Approach (Case study: STMIK Mikroskil). Journal of Theoretical and Applied Information Technology, 97(7), 1891-1901.

Shimp, T. A., \& Kavas, A. (1984). The Theory of Reasoned Action Applied to Coupon Usage. Journal of Consumer Research, 11(3), 795. https://doi.org/10.1086/209015

Sutanto, S., Ghozali, I., \& Handayani, R. S. (2018). Faktor-Faktor Yang Memengaruhi Penerimaan Dan Penggunaan Sistem Informasi Pengelolaan Keuangan Daerah (Sipkd) Dalam Perspektif the Unified Theory of Acceptance and Use of Technology 2 (Utaut 2) Di Kabupaten Semarang. Jurnal Akuntansi Dan Auditing, 15(1), 37. https://doi.org/10.14710/jaa.15.1.37-68

Venkatesh, V., Morris, M. G., Davis, G. B., \& Davis, F. D. (2003). User Acceptance of Information Technology: Toward a Unified View. MIS Quarterly, 27(3), 425-478. https://doi.org/10.1017/CBO9781107415324.004

Venkatesh, V., Thong, J. L. ., \& Xu, X. (2012). Consumer Acceptance and Use of Information Technology: Extending The Unified Theory of Acceptance and Use of Thechnology. MIS Quarterly, 36(1), 157-178. https://doi.org/10.1109/MWSYM.2015.7167037

Witt, C. De, \& Gloerfeld, C. (2018). Mobile Learning and Higher Education Range of technological Solutions. In D. Kergel, B. Heidkamp, P. Kjærsdam Telléus, T. Rachwal, \& S. Nowakowski (Ed.), The Digital Turn in Higher Education (hal. 61-79). Springer Fachmedien Wiesbaden. https://doi.org/https://doi.org/10.1007/978-3-658-19925-8_6.

Wu, J., Wang, S., \& Lin, L. (2007). Mobile Computing Acceptance Factors in The Healthcare Industry: A Structural Equation Model. International Journal of Medical Information, 6, 66-77. https://doi.org/10.1016/j.ijmedinf.2006.06.006

Yakubu, M. N., \& Dasuki, S. I. (2018). Factors Affecting The Adoption of E-Learning Technologies Among Higher Education Students in Nigeria: A structural Equation Modelling Approach. Information Development, 35(3), 1-11. https://doi.org/10.1177/0266666918765907

Yodha, S., Abidin, Z., \& Adi, E. (2019). Persepsi Mahasiswa Terhadap Pelaksanaan E-Learning Dalam Mata Kuliah Manajemen Sistem Informasi Mahasiswa Jurusan Teknologi Pendidikan Universitas Negeri Malang. Jurnal Kajian Teknologi Pendidikan, 2(3), 181-187. https://doi.org/10.17977/um038v2i32019p181

Zhang, W., Wang, Y., Yang, L., \& Wang, C. (2020). Suspending Classes Without Stopping Learning: China's Education Emergency Management Policy in the COVID-19 Outbreak. Journal of Risk and Financial Management, 13(3), 55. https://doi.org/10.3390/jrfm13030055 